Proceedings of the XXIII Conference on Applied Crystallography, Krynica Zdrój, Poland, September 20-24, 2015

\title{
Application of Differential PDF to the Structural Characterization of Supported Catalysts
}

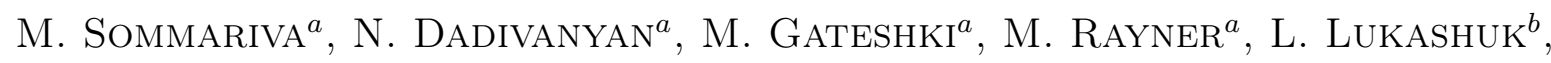 \\ G. RUPPRECHTER ${ }^{b}$ AND K. FÖTTINGER ${ }^{b}$ \\ ${ }^{a}$ PANalytical BV, Almelo, The Netherlands \\ ${ }^{b}$ Institute of Materials Chemistry, Technische Universität Wien, Austria
}

\begin{abstract}
This paper reports the use of a differential PDF approach performed on a laboratory X-ray diffractometer, for the analysis of nanosized $\mathrm{PdO}$ phase distributed on the reducible $\mathrm{Fe}_{2} \mathrm{O}_{3}$ support.

DOI: 10.12693/APhysPolA.130.884

PACS/topics: 61.05.cf, 61.05.cp, 07.85.Jy, 82.45.Jn
\end{abstract}

\section{Introduction}

Catalytic oxidation of $\mathrm{CO}$ is one of several important reactions in the diverse catalysis field, and is key for the treatment and control of automotive exhaust gases, preventing fuel cell poisoning, regeneration of $\mathrm{CO}_{2}$ in sealedoff $\mathrm{CO}_{2}$ lasers, etc. [1]. Nanosized noble metals supported on reducible oxides such as iron and cobalt oxides have been recently found to enhance the catalytic activity in CO oxidation in comparison to non-reducible oxides [2]. Pair distribution function analysis (PDF) based on total scattering data [3] is one of the techniques of choice for the structural characterization of these nanosized catalytic materials, which are often present at very low concentrations and are sometimes amorphous. An advanced application of PDF is the so-called differential PDF (d-PDF), which is based on the subtraction of the PDF of a matrix from the PDF of the system "matrix + guest species", in order to isolate the interatomic correlations of the guest species [4-6]. To enable this approach particular care must be taken in both the data collection (especially reducing the statistical noise in the experimental data) and in the subsequent analysis, because of the weakness of the signal to be analyzed, which results from the difference of the PDFs. In this contribution we demonstrate the application of this method to investigate the structural properties of nanosized $\mathrm{PdO}$ phase distributed on the reducible $\mathrm{Fe}_{2} \mathrm{O}_{3}$ support. Unlike dPDF studies previously reported which were based on synchrotron data [4-6], we used a laboratory diffractometer to collect high energy X-ray diffraction data [7-10].

\section{Experimental}

\subsection{Sample preparation}

$\gamma-\mathrm{Fe}_{2} \mathrm{O}_{3}$ (sample A) from Sigma Aldrich (purity $99.8 \%$ ) was calcined at $400^{\circ} \mathrm{C}$ for $4 \mathrm{~h}$ before use. $\mathrm{PdO} @ \mathrm{Fe}_{2} \mathrm{O}_{3}$ catalyst (sample B) with 5 wt\% $\mathrm{PdO}$ loading was prepared via wet impregnation of $\gamma-\mathrm{Fe}_{2} \mathrm{O}_{3}$. In a typical synthesis, $210 \mathrm{mg}$ of $\mathrm{Pd}(\mathrm{OAc})_{2}$ (Sigma Aldrich, purity $99.9 \%$ ) were dissolved in $\approx 8 \mathrm{ml}$ of toluene, added to $2 \mathrm{~g} \gamma-\mathrm{Fe}_{2} \mathrm{O}_{3}$, and stirred overnight. After that, the catalyst was dried at $100^{\circ} \mathrm{C}$ for $1 \mathrm{~h}$ and calcined at $400^{\circ} \mathrm{C}$ for $4 \mathrm{~h}$. A PdO sample as received from Sigma Aldrich (purity 99.99\%) was used as a reference (sample C).

\subsection{High resolution TEM}

The samples were ultrasonically dispersed in ethanol and then deposited onto holey carbon copper grids for high resolution TEM (HRTEM) (by a TECNAI F20 microscope operated at $200 \mathrm{kV})$.

\subsection{Data collection for PDF and d-PDF}

$\mathrm{X}$-ray total scattering measurements were performed on a PANalytical Empyrean multipurpose diffractometer equipped with $\mathrm{Ag}$ anode $(\lambda=0.5609 \AA)$, a focusing mirror and a GaliPIX ${ }^{3 \mathrm{D}}$ detector with CdTe sensor [10]. The measurements were performed with a variable counting time strategy (VCT) [7] in the angular range $3-148^{\circ} 2 \vartheta$ $\left(Q_{\max }\right.$ value of $\left.21.6 \AA^{-1}\right)$. The time of the measurements was $4 \mathrm{~h}$ for sample A, and $6 \mathrm{~h}$ for samples $\mathrm{B}, \mathrm{C}$ and for the empty capillary.

\section{Discussion}

The total scattering XRD patterns of samples A and B were initially analyzed with the HighScore Plus software [11]; $\gamma-\mathrm{Fe}_{2} \mathrm{O}_{3}$ was found as the main phase (see Fig. 1a), and indications of $\mathrm{PdO}$ present in the sample $\mathrm{B}$ were also found. Conventional XRD was not sufficient to unambiguously identify the nanosized $\mathrm{PdO}$ phase due to peak overlap and peak broadening. The PDF process was then initiated, starting from the initial merging of the diffraction data and the background subtraction in HighScore Plus, and subsequent PDF generation with PDFgetX3 software [12]. The PDFs of samples A and $\mathrm{B}$ were fitted with $\gamma-\mathrm{Fe}_{2} \mathrm{O}_{3}$ phase by using the PDFgui software [13]. Weak mismatches in the fit of sample B occurred at distances corresponding to $\mathrm{Pd}-\mathrm{Pd}$ and $\mathrm{Pd}-$ $\mathrm{O}$ bond lengths (Fig. 1b); a bi-phase fit was also carried out using both the $\gamma-\mathrm{Fe}_{2} \mathrm{O}_{3}$ phase and the $\mathrm{PdO}$ phase, which improved the fit and confirmed the presence of $\mathrm{PdO}$. To isolate the contribution of the $\mathrm{PdO}$ phase the d-PDF analysis was performed. Two different routes were followed to obtain the d-PDF: in one case the diffraction 
patterns of samples B and A were directly subtracted just after the merging of the VCT scans, while in the second case the difference was calculated on the individual PDFs of samples B and A, respectively. Both of these routes produced the same final d-PDF of $\mathrm{PdO}$, which is shown in Fig. 1c, together with the fit performed with the tetragonal palladinite structure. Even with higher noise, the d-PDF is consistent with the PDF of the sample $\mathrm{C}$ (pure $\mathrm{PdO}$ - Fig. 1c) and with the analysis using synchrotron data reported in the literature [6]. Moreover, from the decay of the d-PDF it is possible to estimate the structural coherence length of $\mathrm{PdO}$ particles using the spherical diameter calculation in PDFgui. This was found to be around $7 \mathrm{~nm}$ (where the d-PDF does not show any more structural information). This finding is consistent with the HRTEM image displayed in Fig. 1d, which shows also the lattice plane $0.263 \mathrm{~nm}$ corresponding to the (101) plane of the tetragonal $\mathrm{PdO}$ phase.

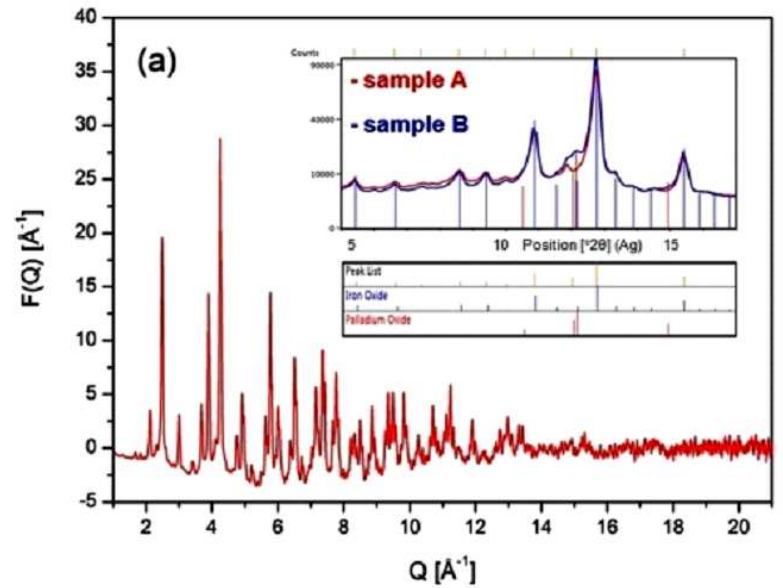

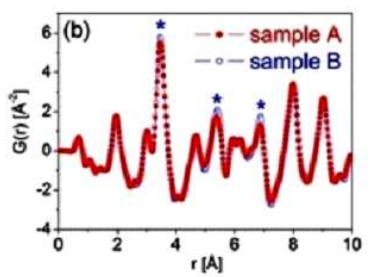

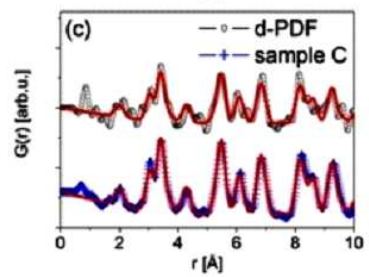

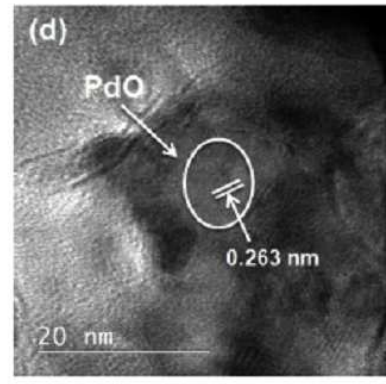

Fig. 1. (a) Reduced structure function of sample A. Inset: diffraction patterns of samples A and B. (b) PDFs of samples A and B. Asterisks mark the main Pd-Pd distances. (c) d-PDF and PDF of sample C (PdO), with fits with the palladinite structure (continuous red lines). (d) HRTEM image showing a Pd-rich area (white circle).

\section{Conclusions}

A differential PDF study was successfully performed on a laboratory X-ray diffractometer to study nanosized $\mathrm{PdO}$ catalyst (5 wt\%) supported on reducible $\gamma-\mathrm{Fe}_{2} \mathrm{O}_{3}$. This type of differential approach is demanding in terms of data quality because the signal to be analyzed is very weak. From the d-PDF it was possible to directly visualize the extent of the structural coherence of the $\mathrm{PdO}$ nanoparticles, which was confirmed by HRTEM.

\section{Acknowledgments}

The authors would like to thank Dr. M. Stöger-Pollach (USTEM, TU Wien, Austria) for the HRTEM analysis. Part of this work was supported by the Austrian Science Fund (FWF) in the framework of the Doctoral School "Building Solids for Function" ("Solids4Fun") [W1243] and by the Austrian Science Fund project [I 2158-N28].

\section{References}

[1] K. An, S. Alayoglu, N. Musselwhite, S. Plamthottam, G. Melaet, A.E. Lindeman, G. Somorjai, J. Am. Chem. Soc. 135, 16689 (2013).

[2] J. Li, G. Lu, G. Wu, D. Mao, Y. Guo, Y. Wanga, Y. Guo, RSC Adv. 3, 12409 (2013).

[3] T. Egami, S. Billinge, Underneath the Bragg peaks: Structural Analysis of Complex Materials, Elsevier Sci. B.V., Amsterdam 2012.
[4] V. Petkov, S.J.L. Billinge, T. Vogt, A.S. Ichimura, J.L. Dye, Phys. Rev. Lett. 89, 075502 (2002).

[5] R. Harrington, D.B. Hausner, N. Bhandari, D.R. Strongin, K.W. Chapman, P.J. Chupas, D.S. Middlemiss, C.P. Grey, J.B. Parise, Inorg. Chem. 49, 325 (2010).

[6] J. Keating, G. Sankar, T.I. Hyde, S. Kohara, K. Ohara, Phys. Chem. Chem. Phys. 15, 8555 (2013).

[7] J. te Nijenhuis, M. Gateshki, M.J. Fransen, Z. Kristallogr. / Suppl. 30, 163 (2015).

[8] M. Sommariva, Solid State Phenom. 203-204, 17 (2013).

[9] M. Sommariva, M. Gateshki, J.-A. Gertenbach, J. Bolze, U. König, B.S. Vasile, V.-A. Surdu, Powder Diffr. 29(S1), 47 (2014).

[10] G. Confalonieri, M. Dapiaggi, M. Sommariva, M. Gateshki, A.N. Fitch, A. Bernasconi, Powder Diffr. 30, S65 (2015).

[11] T. Degen, M. Sadki, E. Bron, U. König, G. Nénert, Powder Diffr. 29(S2), S13 (2014).

[12] P. Juhás, T. Davis, C.L. Farrow, S.J.L. Billinge, J. Appl. Crystallogr. 46, 560 (2013).

[13] C.L. Farrow, P. Juhas, J.W. Liu, D. Bryndin, E.S. Božin, J. Bloch, T. Proffen, S.J.L. Billinge, J. Phys. Condens. Matter 19, 335219 (2007). 